Greenhalgh, J. F. D., Sharman, G. A. M. \& Aitken, J. N. (1969). Res. vet. Sci. Io, 64.

Jamieson, N. D. (1958). Nature, Lond. 181, г60г.

Johnston, T. D. \& Jones, D. I. H. (1966). F. Sci. Fd Agric. 17, 7o.

Long, C. (I96r). Biochemists' Handbook, p. 845. London: E. \& F. N. Spon.

Martin, H., Wörner, W. \& Rittmeister, B. (r964). Klin. Wschr. r4, 725.

Penny, R. H. C., David, J. S. E. \& Wright, A. I. (1964). Vet. Rec. 76, 1053.

Piatkowski, B. \& Steger, H. (1965). Arch. Tierernähr. 15, 447.

Rosenburger, G. (1950). Dtsch. tierärtal. Wschr. 57, 330 .

Rowett Research Institute (1969). Rep. Rowett Inst. for 1968, p. 27.

Smith, J. E. \& Osburn, B. I. (I967). Science, N.Y. 158, 374.

Steger, H., Piatkowski, B. \& Busch, B. (1965). Arch. Tierernähr. 15, 455 .

Steger, H., Piatkowski, B., Busch, B. \& Püschel, F. (1964). Arch. Tierernähr. 14, I I 3.

Tillman, A. D., Sheriha, G. M., Goodrich, R. D., Nelson, E. C. \& Smith, G. S. (1965). J. Anim. Sci. 24, 1136.

Williams, H. L., Hill, R. \& Alderman, G. (1965). Br. vet. F. I21, 2.

Winter, A. J. \& Hokanen, J. F. (1964). Am. F. vet. Res. 25, 353.

\title{
Endocrine control of calcium and magnesium metabolism in ruminants
}

By A. D. CaRe, Rowett Research Institute, Bucksburn, Aberdeen, AB2 $9 S B$

Although the importance of calcium and magnesium homoeostasis has been recognized for many years the precise mechanisms by which this is achieved are still not clearly understood. Over recent years interest in blood calcium regulation has been stimulated by the discovery, isolation and synthesis of calcitonin. Its significance in normal adults, however, remains in some doubt (vide infra). In this paper is outlined our present knowledge of the endocrine factors which help to regulate the control of plasma calcium and magnesium concentration in ruminants through the operation of negative feedback mechanisms. Mention will also be made of those hormones which, although capable of altering the plasma concentrations of either calcium or magnesium, are secreted independently of these concentrations. It will be seen that in many instances the chemical similarity between calcium and magnesium is reflected in hormone effects or in hormone secretion rates. However, this is not always found to be so, e.g. the control of calcitonin secretion appears to be affected in different directions by plasma calcium and magnesium concentrations.

\section{Calcium and magnesium homoeostasis}

It is thought that in adult animals, kept on a diet normal with respect to calcium and vitamin $\mathrm{D}$, an equilibrium exists between bone and blood that is capable of maintaining the plasma calcium at about $70 \%$ of the level usually observed. The remaining $30 \%$ is considered to be under endocrine control. The bulk of this endocrine effect represents the actions of parathyroid hormone with modifying influences imposed by several other hormones. Although the overall ratio of calcium to magnesium in bone is about 50 to $\mathrm{I}$, the ratio of the freely exchangeable fractions of these elements is probably somewhat less but still appreciable. Therefore, endocrine influences which involve changes in bone resorption or accretion rate are likely to have more profound effects on calcium than on magnesium. As far as is known at 
present, endocrine influences on magnesium homoeostasis are usually secondary to some more important effect.

\section{Parathyroid hormone (PTH)}

This is a protein of low molecular weight secreted from the parathyroid glands which, in ruminants, are arranged in two pairs one of which is found in the region of the carotid sinus and the other in close association with the bilobed thyroid gland. PTH raises plasma calcium and magnesium concentrations by stimulating bone resorption, renal tubular reabsorption of calcium and magnesium, absorption of calcium and magnesium from the small intestine and by reducing the secretion of calcium in milk. The bone and kidney effects have both been shown to be mediated through activation of a specific adenyl cyclase present in their tissues (Chase $\&$ Aurbach, $1968 a, b)$. This activated enzyme then catalyses the conversion of adenosine triphosphate to cyclic $3^{\prime}, 5^{\prime}$-adenosine monophosphate (cAMP) which may promote the release of lyosomal enzymes which Vaes (I968) has suggested to be responsible for the stimulation of calcium resorption from bone. The renal effect of PTH is rapid but limited in its capacity. On the other hand, the effect of $\mathrm{PTH}$ on bone is slow to manifest itself as an increase in plasma calcium concentration but is relatively large in its total effect. The extent of the action of PTH on the gut absorption of calcium is generally intermediate between that of the renal and bone actions; it also takes an intermediate period to exert the effect. Thus, in parathyroidectomized dogs, Cramer ( 1963 ) showed that jejunal calcium absorption was restored to normal after a period of $24 \mathrm{~h}$ following the administration of PTH. However, ruminants may be different in their response to PTH. Care, Keynes \& Duncan (I966) showed that although thyroparathyroidectomy of sheep reduced intestinal calcium and magnesium absorption, the intravenous administration of a large dose of bovine PTH to sheep resulted in an initial hypocalcaemic, hypomagnesaemic response which preceded the expected hypercalcaemia and hypermagnesaemia. When this phenomenon was investigated by studying the net absorption of calcium and magnesium from loops of sheep small intestine in long-term surgical preparations, it was found that the initial hypocalcaemic and hypomagnesaemic response could be correlated with failure of calcium and magnesium absorption from the contents of the loops (Care \& Keynes, r964). In collaboration with $\mathrm{Mr} \mathrm{T}$. Duncan, this work was repeated along with the inclusion of ${ }^{47} \mathrm{Ca}$ to enable rates of calcium transport in both directions to be measured. Once again, initial falls in plasma calcium and magnesium concentrations were accompanied by a net loss of calcium and magnesium into the lumen of the intestinal loop. It was found that during the $72 \mathrm{~h}$ following the PTH infusion the calcium absorption rate from the intestine did not exceed that found before the PTH administration, despite the fact that the hormone was infused at about 200 times the calculated basal secretion rate. Presumably the hypercalcaemia observed during this period reflected the resorptive action of $\mathrm{PTH}$ on bone. This peculiar effect of PTH on the absorption of calcium from the alimentary tract has also been noted by Mayer, Ramberg \& Kronfeld (1967) in cows. They injected PTH either subcutaneously or intramuscularly into intact and parathyroidectomized cows 
over periods of $7^{-10}$ days and observed an increase in faecal calcium excretion during both the hypercalcaemic and immediate post-injection periods. The early increase appeared to be due not only to an increment in endogenous faecal calcium but also to a reduction in calcium absorption, whereas the later increase could be attributed solely to decreased calcium absorption. Further experiments are in progress with parathyroid extracts of greater purity in an attempt to eliminate the possibility of the presence of two substances in the PTH preparations used so far which might have opposite effects on the absorption of calcium and magnesium from the ovine small intestine.

For many years evidence has been accumulating to support the contention that the secretion of parathyroid hormone is controlled by the plasma ionized calcium concentration by a negative feedback mechanism. With the advent of a specific radioimmunoassay for PTH and the development of a technique for the controlled perfusion of a parathyroid gland isolated in situ in an anaesthetized goat or sheep, it was possible to obtain unequivocal evidence for an inverse relationship between PTH secretion rate and the plasma calcium concentration (Care, Sherwood, Potts \& Aurbach, 1966). Later work carried out in the sheep in collaboration with Dr J. L. H. O'Riordan, and in the cow by Sherwood, Mayer, Ramberg, Kronfeld, Aurbach \& Potts (1968) has shown that this inverse relationship is linear. A similar correlation has been obtained between plasma magnesium concentration and PTH secretion rate in goats and sheep (Buckle, Care, Cooper \& Gitelman, 1968).

\section{Thyroid calcitonin (TC)}

This is a protein of low molecular weight secreted by light cells found primarily in thyroid but also in parathyroid and thymus of some mammalian species. This hormone inhibits bone resorption so that, in animals in which bone calcium is being rapidly turned over, an injection of $\mathrm{TC}$ brings about a rapid fall in the plasma calcium concentration. Therefore, the hypocalcaemic response to a given increase in the circulating concentration of $\mathrm{TC}$ is greater in lambs than in adult sheep because the bone calcium turnover rate is relatively greater in lambs (Care \& Duncan, 1967). The mechanism by which $\mathrm{TC}$ reduces bone resorption has not been elucidated; it does not act merely to inhibit PTH competitively because it can evince its characteristic hypocalcaemic effect in parathyroidectomized animals.

The significance of TC in calcium homoeostasis has been questioned because of the lack of change in plasma calcium concentration following thyroidectomy, with appropriate replacement of tri-iodothyronine or thyroxine. However, its role in the control of acute hypercalcaemia has been demonstrated in sheep (Inskeep \& Kenny, 1968) and other species. Thus TC may attain some relative importance in the young and in states of calcium stress in mature animals but it seems likely to be minor in comparison to the role of PTH.

The secretion of TC is in direct proportion to the plasma ionized calcium concentration above a set point. This has been clearly demonstrated in both pigs and sheep (Care, Cooper, Duncan \& Orimo, 1968). The secretion rate appears to be 
independent of the age of the sheep in contrast to the hypocalcaemic response to a given dose.

Recent work has shown that TC secretion in the pig may be stimulated by cAMP (Care \& Gitelman, I968). This has now been confirmed in the goat (Care \& Bates, unpublished observations). Evidence from work in pigs has been presented from which it has been suggested that glucagon is able to increase the secretion of TC, possibly by increasing the concentration of cAMP within the thyroid light cells following adenyl cyclase activation (Care, Bates \& Gitelman, 1969). This also has been confirmed in ruminants. However, the significance of these results remains to be assessed, although it may explain the hypocalcaemic action of injected glucagon noted in some species and perhaps the hypocalcaemia of acute pancreatitis.

\section{Thyroxine and tri-iodothyronine}

These hormones increase the bone calcium turnover rate and the amount of exchangeable calcium but are without effect on the absorption of calcium from the small intestine of sheep (Care, I 968). In intact, thyroidectomized and thyroparathyroidectomized sheep it has been found that the intramuscular administration of tri-iodothyronine in oil is followed by a rise in the plasma calcium concentration (Table I). There is also a fall in the plasma magnesium concentration but only in the presence of parathyroid glands. However, thyroidectomy is without effect on the

\section{Table I. Effects of injected tri-iodothyronine* on plasma calcium and magnesium concentrations in sheep}

(Mean values with their standard errors; no. of observations in parentheses)

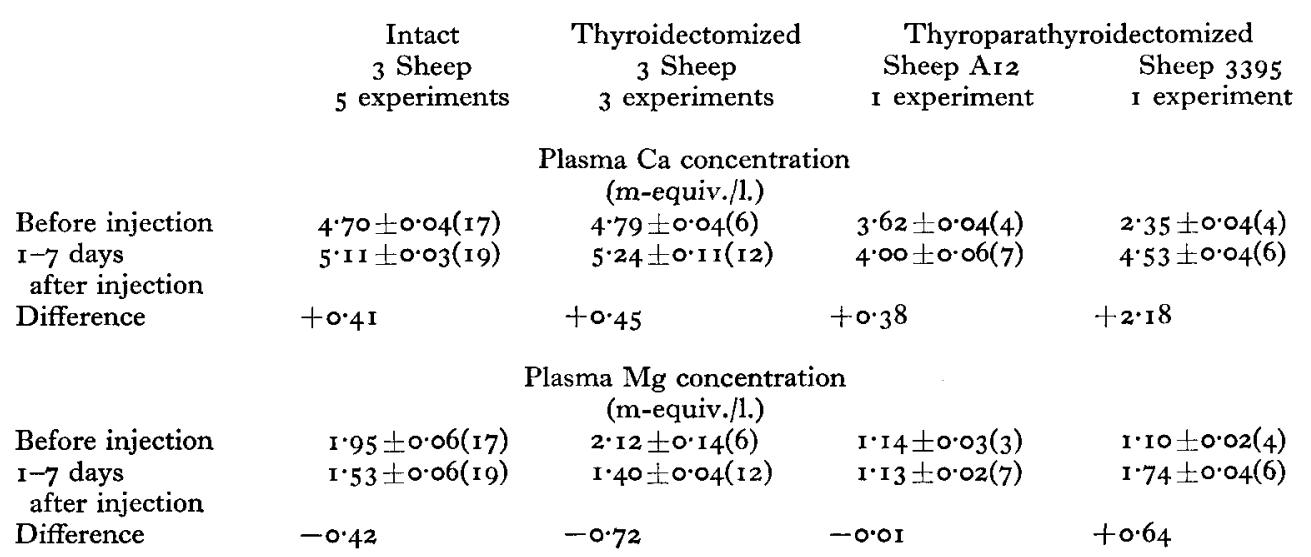

*Two subcutaneous injections of $5 \mathrm{mg}$ L-tri-iodothyronine sodium suspended in $\mathrm{r} \mathrm{ml}$ arachis oil given 2-5 days apart.

plasma calcium concentration in sheep although a rise in plasma magnesium concentration is usually seen. These thyroid hormones increase the tissue turnover of magnesium and also reduce its absorption from the intestine of sheep (Care, Vowles, Mann \& Ross, 1967). As a result of the increased bone calcium turnover rate, 
experimentally induced hyperthyroidism in adult sheep is associated with an enhanced hypocalcaemic response to injected TC. There is also a hyperphosphataemic instead of a hypophosphotaemic reaction to the TC. This effect of thyroxine on the acceleration of calcium turnover can account for its ability to prevent the metastatic calcification associated with overdosage with $\mathrm{P}^{\prime} \mathrm{TH}$ or vitamin $\mathrm{D}$.

\section{Adrenal mineralocorticoids}

Cortisone administration is known to reduce calcium absorption from the gastrointestinal tract and to promote mild hypocalcaemia. Keynes \& Care (1967) demonstrated that aldosterone administration caused hypocalcaemia and hypomagnesaemia in sheep that had been previously thyroparathyroidectomized and adrenalectomized but maintained on regular injections of cortisone and desoxycorticosterone acetate. They went on to show that no negative feedback of calcium or magnesium concentration on the secretion rate of cortisol by sheep adrenal gland appears to exist. This conclusion was extended to aldosterone by Blair-West, Coghlan, Denton, Goding, Wintour \& Wright (I968). The hypercalcaemia associated with cortisone withdrawal in adrenalectomized dogs is dependent upon the presence of the thyroid glands but independent of PTH. This effect of the thyroid appears to be unrelated to calcitonin because thyroxine replacement alone can in thyroidectomized, adrenalectomized dogs restore the response of the bone to hypocortisonism and reproduce the typical hypercalcaemia (Jowsey \& Simons, 1968). The mechanism of this interaction between thyroxine, cortisone and plasma calcium concentration remains obscure.

\section{Endocrine factors in bovine parturient paresis (milk fever)}

For many years this condition has been explained in terms of a relative lack of response on the part of the parathyroid glands. However, with the advent of a sensitive radioimmunoassay for PTH, Mayer, Ramberg, Kronfeld, Buckle, Sherwood, Aurbach \& Potts (1969) clearly demonstrated that in such cases the parathyroid glands were responding in a normal manner and that the circulating levels of PTH were in fact significantly greater than normal.

Abrupt release of excessive TC has also been suggested as a causative factor of parturient paresis, based on comparisons made between the appearance of the thyroid light cells and the thyroid TC contents of cows with parturient paresis and normal animals. Evidence was obtained of greater TC release in the affected cows (Capen \& Young, I 967 ). Since the turnover of $\mathrm{TC}$ in the body is rapid and the bone calcium resorption rate in cows prone to milk fever is low anyway, it seems more likely that a prolonged hypersecretion of TC during the last few days of pregnancy, rather than a sudden release, could bring about the reduction in plasma calcium and inorganic phosphate characteristic of milk fever. Relevant to this is the observation that prolonged intravenous infusion of a relatively small amount of TC to lactating cows with a history of milk fever reproduced both the clinical and plasma electrolyte changes typical of the condition after infusion lasting 9- $17 \mathrm{~h}$ (Barlet, 1968). However, the stimulus for this postulated hypersecretion of TC remains a matter for speculation, although it is noteworthy that perfusion of sheep thyroid with blood rich in 
glucagon is capable of stimulating $\mathrm{TC}$ secretion to levels approximating to those infused by Barlet, when expressed on a body-weight basis (Care, Bruce, Vowles \& Gitelman, I969). The stimulation of TC secretion from a ruminant thyroid gland by a factor other than hypercalcaemia has thus been demonstrated. Blood from cows with milk fever has been assayed biologically for TC-like activity and this has been found to be greater than the concentration in plasma samples from control animals (Barlet, Care, Phillippo \& Lequin, unpublished observations).

Inhibition of bone resorption by the relatively high level of circulating oestrogen noted at parturition has also been suggested as a contributory factor in the aetiology of milk fever (Stott, I 968) but the evidence is somewhat circumstantial. However, it may act synergistically with TC.

\section{Endocrine factors in acute ruminant hypomagnesaemia}

With the observation that hypomagnesaemia was a feature of hyperaldosteronism, it has been suggested that the high potassium and comparatively low sodium contents of the lush grass, often associated with the incidence of ruminant hypomagnesaemia, cause an increased secretion of aldosterone which then leads to a reduction in the absorption of gastro-intestinal magnesium and the development of hypomagnesaemia. This theory was disproved by finding that the plasma magnesium concentration of adrenalectomized sheep, maintained on a constant regime of adrenal corticoids, fell when these sheep were fed lush grass.

It is well known that hypocalcaemia is a feature of many clinical cases of acute hypomagnesaemia. In the light of the known interrelationships between plasma calcium and magnesium concentrations and the secretion rate of $\mathrm{P}^{\prime} \mathrm{TH}$, acute hypomagnesaemia might be caused by a sudden inhibition of PTH secretion. This possibility has been investigated, but a raised level of plasma P'TH was found, indicative of a normal response on the part of the parathyroid glands (Care \& Buckle, unpublished observations).

Until more is known about the mechanisms by which plasma magnesium concentration is controlled the explanation of the pathogenesis of acute hypomagnesaemia will not be forthcoming. It is likely that endocrine factors are only involved to a minor extent.

\section{REFERENCES}

Barlet, J. P. (1968). C.r. hebd. Séanc. Acad. Sci., Paris 267, 2010.

Blair-West, J. R., Coghlan, J. P., Denton, D. A., Goding, J. R., Wintour, M. \& Wright, R. D. (I968). Aust. F. exp. Biol. med. Sci. 46, 371.

Buckle, R. M., Care, A. D., Cooper, C. W. \& Gitelman, H. J. (I968). F. Endocr. 42, 529.

Capen, C. C. \& Young, D. M. (1967). Science, N.Y. 157, 205.

Care, A. D. (1968). Fedn Proc. Fedn Am. Socs exp. Biol. 27, 53.

Care, A. D., Bates, R. F. L. \& Gitelman, H. J. (I969). F. Endocr. (In the Press.)

Care, A. D., Bruce, J., Vowles, L. E. \& Gitelman, H. J. (1969). In Parturient Paresis in Dairy Animals. [J. J. B. Anderson, editor]. New York: Academic Press. (In the Press.)

Care, A. D., Cooper, C. W., Duncan, T. \& Orimo, H. (1968). In Parathyroid Hormone and Thyrocalcitonin (Calcitonin), p. 4r7. [R. V. Talmage and L. F. Belanger, editors.] Amsterdam: Excerpta Medica Foundation.

Care, A, D. \& Duncan, T. (1967). F. Endocr. 37, 107. 
Care, A. D. \& Gitelman, H. J. (I968). F. Endocr. 4r, xxi.

Care, A. D. \& Keynes, W. M. (1964). Proc. R. Soc. Med. 57, 867.

Care, A. D., Keynes, W. M. \& Duncan, T. (1966). F. Endocr. 34, 299.

Care, A. D., Sherwood, L. M., Potts, J. T. \& Aurbach, G. D. (1966). Nature, Lond. 209, 55.

Care, A. D., Vowles, L. E., Mann, S. O. \& Ross, D. B. (1967). F. agric. Sci., Camb. 68, 195.

Chase, L. R. \& Aurbach, G. D. (1968a). In Parathyroid Hormone and Thyrocalcitonin (Calcitonin), p. 247. [R. V. Talmage \& L. F. Belanger, editors.] Amsterdam: Excerpta Medica Foundation.

Chase, L. R. \& Aurbach, G. D. (r 968b). Abstracts of Brief Communications, Third International Endocrine Congress, p. 87. International Congress Series no. I 57. Amsterdam: Excerpta Medica Foundation.

Cramer, C. F. (1963). Endocrinology 72, 192.

Inskeep, E. K. \& Kenny, A. D. (1968). Endocrinology 83, 183.

Jowsey, J. \& Simons, G. W. (I968). Nature, Lond. 217, I277.

Keynes, W. M. \& Care, A. D. (1967). Proc. R. Soc. Med. 6o, г 136.

Mayer, G. P., Ramberg, C. F. \& Kronfeld, D. S. (1967). F. Nutr. 92, 253.

Mayer, G. O., Ramberg, C. F., Kronfeld, D. S., Buckle, R. M., Sherwood, L. M., Aurbach, G. D. \& Potts, J. T. (1969). Am. F. vet. Res. (In the Press.)

Sherwood, L. M., Mayer, G. P., Ramberg, C. F., Kronfeld, D. S., Aurbach, G. D. \& Potts, J. T. (1968), Endocrinology 83, 1043.

Stott, G. H. (1968). Fedn Proc. Fedn Am. Socs exp. Biol. $27,{ }_{56}$.

Vaes, G. (1968). In Parathyroid Hormone and Thyrocalcitonin (Calcitonin), p. 318. [R. V. Talmage and L. F. Belanger, editors.] Amsterdam: Excerpta Medica Foundation.

\section{Ghronic copper toxicity of ruminants}

By J. R. TodD, Ministry of Agriculture, Veterinary Research Laboratories, Stormont, Belfast, $\mathrm{BT}_{4}{ }_{3} S D$

There has been an active interest in the toxicology of copper since the middle of the I $9^{\text {th }}$ century and a review by Davenport ( 1953 ) covers the early work on the hazard to man and animals of both the acute and chronic forms. Review material specific to chronic copper poisoning in farm livestock has also been published by Broughton \& Hardy (1934), Eden (r940), Todd (1962) and Bull (r964).

The first description of true chronic copper poisoning in farm animals would seem to be that of Mallory (1925) who produced the condition experimentally in sheep. Beijers (1932) described similar symptoms in sheep grazing orchards which had been sprayed with a copper fungicide, and 2 years later Broughton \& Hardy (1934) published their detailed experimental investigations showing the dangers of excessive copper intakes to sheep. The similarity between the symptoms described in these reports and those of 'yellows' or 'toxaemic jaundice' in Australia was recognized (Bull, 1964) and the experiments of Albiston, Bull, Dick \& Keast (1940) confirmed that this naturally-occurring condition was of similar origin. The importance of chronic copper poisoning as a nutritional hazard was, therefore, fully established.

More recently the danger has arisen under different circumstances in the British Isles, and it is now recognised that excessive accumulation of copper is one of the hazards when sheep are maintained indoors for prolonged periods.

\section{Toxic syndrome}

The clinical picture of chronic copper poisoning is characteristic and is quite 